Article

\title{
Becoming a Shaman: Narratives of Apprenticeship and Initiation in Contemporary Shamanism
}

\author{
Carolina Ivanescu * ${ }^{(1)}$ and Sterre Berentzen \\ Department of Religious Studies, University of Amsterdam, Kloveniersburgwal 48, 1012 CX Amsterdam, \\ The Netherlands; sterre.berentzen@student.uva.nl \\ * Correspondence: c.ivanescu@uva.nl
}

Received: 13 June 2020; Accepted: 13 July 2020; Published: 17 July 2020

\begin{abstract}
This article, based on an open-question survey completed in 2018, engages with McAdams and Manczak's approaches to life stories (2015) and Mayer's ten elements of the shaman myth (2008) to explore the way contemporary people based in the UK, who define themselves as shamans, talk about their becoming a shaman. Individual narratives point out the intricate meeting points between different shamanic traditions and the importance of continuous innovation. They highlight the complex network of human and beyond-human authority and problematize the place, meaning and agency of the self. Contemporary shamanism is a widespread, manifold and multifaceted phenomenon, which we argue is not as different from traditional forms of shamanism as some studies suggest.
\end{abstract}

Keywords: traditional and neo-shamanism; contemporary western shamans; apprenticeship; initiation; agency and hierarchy; narrative construction; UK

\section{Placing Shamans in Context}

Shamanism is said to be one of the oldest forms of religion, with shamans as the traditional, indigenous and holistic specialists in charge of their trade. This view has been promoted and also criticized, the latter especially by pointing out its constructed, or in some cases 'invented', nature. Shamanism in a traditional sense is local, and its knowledge is culture-bound and linked strongly to a ritual system (Walsh 1990, pp. 15-17). However, there also are quasi-universal elements to be found across different types of local, ethnic or indigenous shamanism, elements which can make different local practices seem like variations of certain types of religious practices, namely shamanism. Thereby, cross-cultural definitions of shamanism have appeared (Eliade 1964; De Heusch 1981; Lewis 1989) which have shaped the understanding of what the contours of the category of shamanism are. Although they have been widely criticized in scientific circles, these universal categories are still very popular in contemporary practices (Noel 1997; Wallis 2003; Znamenski 2007; Boekhoven 2013). Thus, the tension between particular and universal traits and characteristics remains not only at the center of the discussion about shamanism in its traditional forms, but also at the center of its practice in its current forms. In our contemporary society, people 'who consider themselves to be shamans or to be doing 'shamanic' things' (Harvey 1997, p. 107 cited in Wallis 2003) are a rather large and diverse group.

These 'shamanic' things mentioned by Harvey are western in nature and mostly urban-based, but can be (to various degrees) connected to shamanic traditions, and in some cases are built on a mix of different traditions. They are known in the research literature as neo-shamanism (Wallis 1999; Davidov 2010), a term closely related to Core shamanism, Harner's modern, simplified and universalistic way of practice (Harner 2009). Both neo-shamanism and Core shamanism fall, according to Townsend, under the category of 'modern shamanic spirituality' (Townsend in Walter and Neumann Fridman 2004, pp. 49-58). People involved in these practices consider themselves either 
practitioners of shamanism or shamans. We are interested in the way people come to understand themselves and the things they do as shamanic, the way they appropriate a certain vocabulary and the type of words, images and metaphors they use in order to explain who they are and what they do, and most of all, in the process of becoming a shaman in a modern context. A crucial—and to our knowledge novel-means of understanding modern shamanism and especially its relationship to traditional shamanism is to examine self-narratives. Narratives allow us to probe people's understanding of how they became shamans and what their roles as shamans are. Given that both the transition into shamanhood and the understanding of what a shaman stands for are central features of the practice, narratives allow us to study critical features of shamanism that would be difficult to pinpoint with other methods.

To this purpose, we use the results obtained from an open-ended, internet-based survey, which was based on the existing literature on shamanism and shamanic practices. In this article, we engage with the answers given by respondents from the United Kingdom who considered themselves a shaman and with questions related to the process, experience and definition of becoming a shaman. The extensive answers were analyzed as narratives, firstly by using McAdams and Manczak's construction of identity through life stories models (McAdams and Manczak 2015) for a structural comparison between different narratives and secondly, by using Gerhard Mayer's attributions of a shaman (Mayer 2008) for a thematic comparison between different narratives. At the core of the narratives are definitions of what a shaman is which are related to the identity of the narrator and the accounts of experiences in the process of becoming. We interpret these self-definitions and experiences, based on our two-fold analysis, and reflect on them through the characteristics of traditional shamanism and neo-shamanism as described in the literature, which we use as points of reference. In other words, in this article we are interested in comparing among narratives of becoming a shaman in order to understand how contemporary shamans see themselves and their practices, as well as to see how these narratives relate to accounts in the existing literature on different forms of shamanism. The narratives, therefore, are central to this article. By looking at self-narratives to understand contemporary shamanism and its relation to traditional shamanism, we sought to highlight the importance of using 'experience' and narrative as the object of research of contemporary forms of shamanism.

\subsection{Becoming and Being a Traditional Shaman}

Mircea Eliade, whose work has influenced not only the study but also the practice of shamanism (Wallis 2003), identifies shamanism, comparing its different traditional forms as an 'archaic technique of ecstasy' and defines the shaman as 'a psychopomp, and he may also be a priest, mystic, and poet' who both cures and performs miracles (Eliade 1964, p. 4). According to Eliade, the shaman is beyond space and time. He lives in the mythical dimension, which enables the envisioning of continuous cycles of death and rebirth. He crosses and travels at will between different realms of existence, and communicates directly with spirits, animals and plants. Through ecstasy, which according to him is the foremost 'technique' of shamanism, the shaman enters and leaves this primordial and universal state of being human, being permeated by the 'mysteries' of nature at will. The shaman undertakes these crossings on behalf of individuals, but also for the collective good. According to Eliade, through the shaman, one can access the experiences which have been lost to the ordinary person. This is something the shaman learns to do through his own experiences (Eliade 1964).

Though in most cases the shaman is a 'general practitioner', shamans are described as playing a great diversity of roles that can be divided into 'subspecialties', (Lenski 2013). Most importantly, shamans are said to mediate between different realms of existence such as that of humans and those of spirits, and between different types of spirits and humans, but also among humans. This mediation takes place first of all, but not only, between the so-called upper and lower realms of existence where spirits of different kinds reside (see, for example, Eliade 1964), but also mediate 'divisions of caste and class relations' in between humans, according to Taussig (1991). Travelling or journeying between the realms and worlds (Blain 2003) happens most of the time but not exclusively, through ecstatic 
methods, with or without the help of plants (some of them entheogens) or animal allies, and through the use of different tools, of which drums and rattles are the most well-known. In some cultural contexts, journeying is replaced or complemented by instructions received in dreams (Handelman 1967; Holmberg 1983). The use of allies and tools is connected to techniques which are learned. Learning or receiving these skills is an important part of becoming a shaman.

In most cases, shamanic powers are inherited and developed either through blood ties between shamans (in this case we speak of hereditary lineages), or through significant teacher/disciple relationship(s), where unbroken lines of initiation are important (Lindquist 2005). Unbroken lines of initiation refer to strong and continuous teacher-student relationships, where knowledge and skills are transmitted from person to person through formal apprenticeship. These powers are special in a spiritual but also in a social sense. Diószegi, researching Central Asian forms of shamanism, teaches us that becoming a shaman is also possible through non-human lineages: talent and powers may be inherited, but they also can be acquired without learning from a human teacher or receiving them from a (shaman) ancestor. An important role in becoming a traditional shaman, Diószegi mentions, is the spirits, who determine not only if one becomes a shaman but also the power one is able to possess and use. The spirits are the ones who will decide if blood ties or in-person learning is to be of effect, as 'all shamans, whether they stem from a shaman family or not, become shamans at the wish of the spirits only' (Diószegi 1960, p. 150). In the context of his research, Diószegi observed that shamans become more or less powerful as they are influenced by the capacities of their spirits. They are affected also by the nature of spirits, which influences if one becomes a white/benevolent/healer or black/harming/magician shaman (see also Birx 2005, p. 2080). If blood ties and in-person contact are not essential for becoming a shaman, the locality and place-boundedness of transmission is widened, cancelling the exclusively local character of shamanic knowledge.

As spirits play such an important role in shamanism, it is worth exploring what or who these spirits are. In the Central Asian context, spirits are related to everything that exists, such as persons, animals, plants but also to objects. Elements of nature such as places, rivers, mountains also have spirits, while ancestors and so called 'master spirits', or spirits which are beyond the material realm, also exist. The knowledge of these spirits is not bound by space as 'the spirits and ghosts know everything because being bodiless they can get everywhere' (Diószegi 1960, p. 8). Shamans establish contact with these entities, communicate and are able to gather them and share the knowledge received from them for the purpose of sharing it with those in need or with the larger community they are part of. The shamans are not acting for themselves, but on behalf of others, individuals or a whole community. While in some cultures there exists a hierarchy between spirits depending on their power, in most cultures we only see hierarchy in the subordination of the shaman to the spirits and in the subordination of the non-initiated humans, or the 'clients' of the shaman to the shaman itself.

Shamanic activities happen within the context of a culture which has a place for shamanic activities not only through an adequate cosmology but also through a social context which recognises and values the activities of a shaman. As far as the social context is concerned, recognition of a shaman by the members of a group and use of the shaman's services is crucial (Reinhard 1976). Singh explains that the recognition of a possible shaman is very often social and it is based on markers which are recognized by the community and which are related to some kind of 'innate peculiarity, such as perennial illness (Lebra 1966; Schefold 1988), an extra finger (Bernstein 2008) or ambiguous sexual identity (Coleman et al. 1992; Peletz 2006; Singh 2018). Such characteristics single out individuals more capable of becoming shamans. Serious, mostly terminal illnesses, followed by miraculous recoveries are seen as signs of the ability of a person to heal oneself (thus the wounded healer trope is strongly connected to shamans) and healing others. Indeed, these illnesses and physical peculiarities are seen as being initiatory in nature, part of the 'call' of the spirits and thus also part of the process of becoming a shaman. As a practitioner mentions, in most cases an initial illness is perceived as a trial but is not necessarily the same experience as the individual's actual initiation into being a shaman (Pratt 2007). All these 'signs' are tendencies rather than confirmations. 
Recognition as a possible shaman signals the beginning of a long (Pritzker 2000) and often arduous process of apprenticeship. The trials an apprentice goes through either stop completely after the initiation or continue for a lifetime (Singh 2018). It is during these trials that the tools of the trade are learned or received. In some traditions, these tools can be used before a proper initiation, in other traditions they depend on the initiation and only after being 'reborn as a shaman' can one master and use techniques such as songs, rituals, and knowledge or experience of medicinal or entheogenic plants (Birx 2005, p. 2079).

The end of the period of apprenticeship is a trial, mostly taking place as a form of symbolic death or dismemberment, which then will be repeated several times throughout one's life as a shaman. This trial is mentioned as an initiation. Eliade considered a dismemberment experience, dream or vision in which the shaman is taken apart in some way by helping spirits as a common and essential feature of shamanism (Eliade 1964). However, this step is not essential in all cultures, according to a shamanic practitioner (Pratt 2007). Nevertheless, in most contexts, becoming a traditional shaman remains a complex and difficult process, where one's life is often also at stake: 'Becoming a shaman isn't simple. There has to be some kind of difficult journey, a process with complex spiritual, social and personal repercussions, and if you survive it, you'll be okay' (Levin 2019, p. 175).

The apprenticeship is an important element in the process of becoming a shaman. The literature concerning the apprenticeship of traditional shamans distinguishes different models. Lewis (2003) makes a distinction between two phases of apprenticeship: one human, implying a line of transmission between humans, thus from a shaman to an apprentice, and one spiritual which involves spirit(s) and intermediary beings. Another model of apprenticeship is proposed by Wilson (2013), who considers the process of becoming a shaman as beginning with an initial possessory experience, a phase of development and learning from humans and/or spirits, and ending with the point of recognition of 'having the ability to manage his psychic experiences, so that he is no longer personally at risk, and is able to use his spiritual skills in ways (such as healing) that are recognized as being valuable to other members of the community'.

While considering these accounts of traditional shamanism, we need to mention that some of them, especially Eliade's work and his definition of a shaman, are considered essentialist and thus need to be looked at critically. This does not mean, however, that such ideas have not had a crucial impact on the modern practices of shamanism (Noel 1997; Wallis 2003; Znamenski 2007; Boekhoven 2013), where exactly universalistic, essentialist and context-neglecting perspectives have gained influence, as we will discuss in the following part.

\subsection{Neo-Shamanism: Say What?}

Shamanisms, traditional or new, never happen in isolation, but are always 'embedded in wider systems of thought and practice' (Atkinson 1992, p. 315). In the same way as shamanism was described as an universal practice of making connections with the spiritual realm(s) through 'ecstasy' (Eliade 1964), neo-shamanism is proposed as a general category of practice for the western world (Lindquist 1997). Neo-shamanism implies a distinction between traditional shamanism, based on tradition and lineage, passed down from generation to generation within specific cultural traditions and social formations and 'improvised, provisional shamanic rituals and experiences often born within workshop settings and informed by past (or recent) ethnographic literature' (DuBois 2011, p. 111). Traditions are, in neo-shamanic points of reference, being 'revived, rediscovered or reinvented' (Blain and Wallis 2000, p. 395) as part of the personal 'identity business' (Comaroff and Comaroff 2009, p. 74).

Neo-shamanism is said to result in large measure from the circulation of the literature on shamanism (shamanovels and shamantropology according to Noel 1997; see also Von Stuckrad 2005; Znamenski 2007). It makes use of altered states of consciousness and engagement with other life forms such as spirits or helpers ('allies') for purposes such as healing, upgrading to a higher consciousness and finding the true, authentic self. In this regard, neo-shamanism is an individualist phenomenon (Hutton 2007) which is based on direct spiritual experience (Adler 1979) and lacks the social role 
and purpose of its traditional counterparts, processes which have been described by Townsend as the democratization of shamanism (Townsend 2005, p. 5). Shamans in this context seem to be able to move between worlds and between different realities. Most present-day shamans seem to be cosmopolites with mobility-filled lives, many of whom move easily between realms of traditional religion and healing or corporate environments. Flexibility also implies transnational mobility and 'religious foraging' (Farahmand and Rouiller 2016). For most of them, the issue is not authenticity, as they do not try to reconstruct practices exactly as in the past, but rather flexibility, the capacity to adapt and translate between different environments, which might be characterized as a characteristic of the neoliberal subject (Mitchell 2003; Freeman 2011). Authenticity in this sense refers to the specific and culture-bound characteristics of beliefs and practices.

The specificity of neo-shamanic practice is two-fold: on the one hand, the reappropriation of the pure 'other' traditions, and on the other hand, their incorporation into an already existing system of belief, as part of a quest for authenticity, 'roots' (Lindquist 1997) and self-development (Boekhoven 2013, p. 247). This system of belief is individual, while authenticity is connected to a sense of authority which can be borrowed from what is seen as tradition. In this context, tradition is closely related to the idea of identity and becomes, as Friedman explains, connected to an 'ongoing process of negotiation and struggle' (Friedman 1992, p. 18). This also means that individual experiences do not necessarily need to be recognized by others; social embeddedness is not necessary for becoming and being a shaman. According to practitioners of shamanism, the role of the shaman is first of all that of healing and being a visionary (Ingerman and Wesselman 2010), healing, which includes care of the self and possibly of others, self-actualization (Noll 1989), but also a healing relationship with nature (Achterberg 2002). However, the social maintains its importance through becoming an audience (Friedman 1992) and thus also a witness in the search for spiritual values through the 'method' that shamanism is considered to be (Znamenski 2007, p. 168). In this sense, shamanism is reduced to being one of the many different ways or methods to develop and reach the authentic self.

The process of becoming a shaman has become 'a distinct literary category' (Clifton 1994 in Wallis 2003, p. 1), populating entire shelves in bookstores and libraries. Neo-shamanic accounts of becoming emphasize experience and its authenticity, relations of learning based on human to human and human to spirit encounters and transmissions of knowledge and power. The spirits met are not necessarily local, just as the use of allies is transcultural. The trust in them also increases; spirits are not necessarily submitted to scrutiny, but are accepted readily as guides (Burkett 2005). Indeed, shamanism has grown into a global scene where human and non-human actors from both indigenous cultures and western countries mingle and share, without distinct hierarchies and where techniques are borrowed, renewed and mixed on a larger scale (just like traditional forms of shamanism that are never static either) and the (authentic) self becomes the ultimate goal but also the ultimate authority on such 'spiritual' matters.

As individual experiences are crucial both in traditional and neo-shamanic contexts, in this article we explore the self-narratives of becoming a shaman, in which contemporary individuals who identify as a shaman make sense of their experiences and, while speaking, (re)shape their sense of self (McAdams and Manczak 2015). This is what we focus on: How do contemporary shamans talk about their becoming and being a shaman? How do they see themselves and their practices? How do they communicate their experiences when talking about themselves?

\section{Materials and Methods}

This article is based on a survey collecting the narratives of shamans and shamanic practitioners who are active online. The complete survey consists of a total of 44 questions, of which 15 were multiple-choice questions and 30 open-ended ones. Seven questions aimed at collecting general details. Respondents could choose which questions they wished to answer, allowing partial responses. The survey was initially built on the Survey Planet free platform, ensuring that a link could be shared 
with the possible participants. For the purpose of data retrieval, during the research an upgrade was made to the Pro version of the same platform.

The link to the survey was posted as a trial in February 2018 on an international online community group of shamans, with the approval of the admins. In the text accompanying the link to the survey we requested help, stated the scientific and academic purpose of the study and invited people to contact the author with any questions/comments. The survey was posted subsequently during the month of February on several similar groups for shamans or shamanism, following the same procedure. The data collection was closed at the end of March 2018. For the purpose of this article, the results have been filtered to include only: (1) respondents from the UK which have self-identified as shamans and (2) answers given to a limited amount of questions (namely Q3, Q4, Q6, Q8, Q9, Q12, Q13 and Q38, Q39, Q40, Q42 for general, contextual information about the respondents which can be found in Appendix A). The selection for the UK was purely practical. After receiving answers from 163 respondents, we decided to narrow down our research to the UK, which had the most respondents per country with a positive answer to the question as to whether they considered themselves a shaman. From the 44 questions the survey consisted of, we chose to focus on the ones which dealt with becoming, skills, and networks as the topic of our discussion focuses on the process of becoming a shaman. At the end of this selection, the sample for this article consisted of 14 respondents and their answers to seven questions. Details about the age, gender, education, relationship status and place of residents of the respondents are visible in the table below (Table 1).

Table 1. Contextual factors of the respondents.

\begin{tabular}{|c|c|c|c|c|}
\hline Respondent & Age & Gender & Education & Place of Residence \\
\hline $1^{1}$ & $55-64$ & Male & Some college credits, no degree & In the countryside \\
\hline 9 & $55-64$ & Female & High school graduate, diploma or the equivalent & In the countryside \\
\hline 18 & $55-64$ & Male & Professional degree & In the countryside \\
\hline 24 & $65-74$ & Female & Trade/technical/vocational training & In a city \\
\hline 26 & $45-54$ & Female & Bachelor's degree & In a smaller town \\
\hline 40 & $55-64$ & Male & High school graduate, diploma or the equivalent & In a smaller town \\
\hline 65 & $55-64$ & Female & Trade/technical/vocational training & In the countryside \\
\hline 71 & $35-44$ & Male & -2 & In the countryside \\
\hline 81 & $45-54$ & Male & High school graduate, diploma or the equivalent & In a city \\
\hline 88 & $35-44$ & Male & Some college credits, no degree & In a smaller town \\
\hline 96 & - & - & Professional degree & In the countryside \\
\hline 129 & $55-64$ & Female & Master's degree & In the countryside \\
\hline 143 & $55-64$ & Female & Bachelor's degree & In the countryside \\
\hline 154 & $65-74$ & Female & Trade/technical/vocational training & In the countryside \\
\hline
\end{tabular}

${ }^{1}$ Bold in this table indicates the respondents whose answers were used for the case study. ${ }^{2}$ The hyphenate in this table indicates that the respondent omitted to reply this question.

These contextual factors have not been used in our analysis, which focuses on the text of the narratives, following Geertz's idea that culture can be read as an assemblage of texts (Geertz 1973). Our respondents accounts are narratives about themselves, which we analyze as such by using two methods: McAdams and Manczak's aggregation of life story approaches and Mayer's attributions of the shaman, therefore looking at the narratives as structures of constructing meaning and narratives as building upon tropes.

On the basis of the results of this analysis, we then reflect on the literature concerning shamanism and neo-shamanism. In this body of literature, we also encounter narratives about and of, and interpretations of narratives about and of, different forms of shamanism.

\section{Shamans Talking about Themselves: Exploring Contemporary Narratives}

Growing interest in identity construction and the role of discourse in its construction has attracted a lot of attention in the last two decades (Elliott 2005). While there is still no single or standard approach which is generally recognized as representing the narrative method of analysis, narratives can be 
defined as 'discourses with a clear sequential order that connect events in a meaningful way for a definite audience' (Hinchman and Hinchman 1997). This definition encloses three important features of narratives: 'the temporal nature of social life as providing a rationale for a narratively informed methodology', 'the evaluative or subjective dimension of narratives and their ubiquity within everyday social interaction', and the 'social processes surrounding the production and consumption of narratives' (Elliott 2005, pp. 36-37). Although most researchers focus on one of these dimensions of narratives, we decided to analyze our material while taking into consideration the three features noted above.

As a story evolves, a self-narrative is internalized by the storyteller for the purpose of making sense of their life over time. This is called the life story. These stories provide the storyteller with some semblance of unity, purpose and meaning. They are shaped by contextual factors such as culture, religion and class and draw upon one's own experiences. This makes them psychosocial constructions of the self. Research on life stories and personal narratives first appeared during the 1970s and 1980s. McAdams (1985) life story model of identities brought three dimensions of the life story forward. This model interpreted the life story as an integrative story answering the questions: Who am I? How did I come to be? Where could my life be going? It is the constructed past and the imagined future (McAdams and Manczak 2015). Researchers on life stories have developed structured interviews that paralleled the categories people often organize their life by, for example, broad periods in life, recurrent events, and specific scenes that stand out in their significance. Although this model has been developed for narratological life story interviews, it can also serve as a tool for analyzing other forms of narrative data. By using the life story analysis on our respondents' narratives, we can look at the way these respondents place the becoming of a shaman in their life stories and how this determines their role as a shaman.

As a second way of looking at our narratives, we chose to look at the narratives of selected respondents in terms of the coherence of the whole story, the most important details and the foremost messages which the respondents wanted to convey. For this purpose, we made use of Mayer's attributions of the shaman (Mayer 2008). Mayer identifies ten different possibilities of interpretation of what a shaman can be, which are all part of the 'myth' of the shaman as constructed and understood by western societies. For this purpose, he describes four areas which refer to the image of the shaman: the neo-shaman, the urban shaman, technoshamanism and cybershamanism. These areas point to the different sources of inspiration and knowledge relevant for contemporary shamans, sources which partly come from traditional shamans and partly from elsewhere. We identify these attributions in each account and compare them to each other. Surprisingly, not all of the attributions mentioned by Mayer are present in our respondents' narratives.

Reflecting on the literature on becoming and being a shaman in the traditional sense and the literature on neo-shamanic forms, we have identified some specific elements which we could expect to resurface in our material. Regarding both traditional shamanism and neo-shamanism, there seems to be a pattern of particulars, almost tropes, for the narrative of becoming a shaman, as outlined in the introduction. Within traditional shamanism, Wilson (2013) sets out a clear model of apprenticeship which roughly entails an introduction, the apprenticeship itself, the initiation and the recognition. According to him, the introduction mostly involves some kind of possessory experience (Wilson 2013) or some kind of physical or mental peculiarity which is recognized by the community as a sign or mark of a potential shaman (Singh 2018). The apprenticeship is the period in which the individual learns the techniques and skills of shamanism, the most important being the journeying between realms (Blain 2003) and the ability to make contact and communicate with spirits (Wilson 2013). The apprenticeship ends with an initiation by means of a trial, mostly constituted by a symbolic death or dismemberment. The period of 'becoming' ends with the recognition of the individual's skills by the community, wherein these skills are seen as valuable to other members of the community (Wilson 2013). The spirits play an important role throughout the process, as they are responsible for the powers a shaman acquires and uses (Diószegi 1960). Therefore, a shaman can only be fully recognized as a shaman by the spirits. 
Within neo-shamanism, becoming a shaman does not have a clear linear structure, but three features are recurrent: the initial experience, the learning process and self-healing. The initial experience is individual and concentrates around a reappraisal of one's own position in a complex universe. To become a shaman, one must first be able to heal oneself, before possibly healing others (Noll 1989). This is also visible in how practitioners speak about these issues. As it is individual, it does not necessarily need to be socially recognized (Ingerman and Wesselman 2010). The learning process is also individual, and the individual remains in charge of what and how it is learned. An individual is able to heal by using altered states of consciousness and by engaging with beyond-human life-forms which can also teach skills (Adler 1979).

\subsection{Contemporary Narratives-Tropes and Coherence: Who Is in Charge?}

The developed narrative construction analyzing systems, as outlined in the beginning, look at the respondents as autobiographical authors who place the apprenticeship of becoming a shaman in these stories. These analyzing systems access themes of agency and communion, redemption and contamination, narrative coherence, and variations of the ideas of autobiographical reasoning and meaning-making (McAdams and Manczak 2015). The respondents were not asked to tell their life story, but were given questions that made them reflect on who they are, how they became this person and how they see themselves in relation to other shamans. While studying their answers according to the narrative construction analysis, we reflected on what the respondents said and how they said it. Some took the opportunity to give us a very detailed narrative of their life story in just one answer, others answered the question more directly and in a few words. However, all these answers given by one respondent form a single compact assembly together. Taking this into account, we looked at the whole narrative per respondent, analyzed it by the themes of narrative construction and put all the different forms of one theme alongside each other, thereby reflecting on the individual and collective levels.

Agency and coherence are two concepts originating from J. Adler's longitudinal study of narrative identity development and mental health (Adler 2012). His focus on agency and coherence is premised on the dual aims of narrative identity: purpose and unity. Agency in narratives is understood as the manner in which the protagonist can affect their own lives and achieve some degree of control over the course of their experience, and, by extension, their self-sufficiency. Where agency represents purpose, coherence represents unity. Coherence is the degree in which the protagonist sufficiently describes the background information of the story, or details about the setting for the narrative that follows (Adler 2012). It is also the degree to which the narratives have a causal sequence or a thematic integration (McAdams and Manczak 2015).

Among our respondents, the degree of agency of the person differed strongly. Sometimes they did not experience any choice but were assigned by the spirits, like Respondent 1: 'I first became aware of the spirits when I was 15 and they started teaching me.' To the question whether they had received an initiation, the participant responded with: ' [ ... ] I don't require a shanar [dedication ritual of a Buryat shaman], as the spirits have given me one incrementally over the years.' Respondent 71 answered that 'the Earth called, leading to expansive revelation experiences.' Much more often, it was the person who was exploring themselves by research or practice or suffering a serious illness, who then had a spiritual experience during which the spirits visited, and after which they chose this path. Respondent 24 became very ill and did not expect to live. 'In my weakened state, [these] same spirits returned and told me I could live if I chose to work with them. I chose life and they taught me.' While one of the respondents mentions agency in giving empowerment, thus talking about a transition of agency from the spirit realm into the respondent's; for others, agency is framed in terms of answering to a call and experiencing unexpected results. This element of surprise seems to be present in more accounts. In most cases, the element of surprise is provoked by the choice given by the spirits, considering that it is the person who willingly gives up their agency for a life full of surprises controlled by the spirits.

Considering coherence as the causal sequence evident in the responses, most responses display a high degree of coherence. The question: 'In what way has your interest in shamanism changed you?' 
stimulated people to reflect on their stories and made people think about the causal sequence of their story. This causal sequence manifests itself in two ways: Whereas most respondents talked about the change in themselves, others mentioned perceiving the world around them differently. The changes in themselves included behavioral changes, like in Respondent 9, who stated that their interest in shamanism had 'realigned [them] to [their] work,' or in Respondent 18, who felt 'less tolerant of new age nonsense.' When coherence is present in the display of the surrounding world, the responses do not necessarily consist of a change. They could also be retrospective, like Respondent 65, who mentioned: 'throughout my childhood the spirit world was close and continued to be all throughout my life.'

In contrast with agency, communion is not about the respondent as an individual manifesting her/himself, but about the participation of the respondent in some larger community or organization. For McAdams et al. (1996), these two categories are the central thematic lines in the stories people construct to provide their lives with unity and purpose. At its core, communion involves different people coming together and having communicative relationships. This concept of communion can be subdivided into four categories: lovelfriendship, dialogue, care/help, community (McAdams et al. 1996). Especially the category community as belonging to some larger community, experiencing a sense of unity or solidarity with a group of people or even with all of humankind, reappears in the answers of the respondents. Most respondents feel connected with the spirits or spirit allies, with the whole earth and all of mankind, and sometimes they also feel connected to other shamans through the work they do. Respondent 9, for example, has found shamanism 'via lineage and past lives,' and is now 'of service.' This work is part of the category care/help, which all respondents feel to be one of their functions in the shamanic life. Some state to 'be at service for humanity' or 'being a channel for healing others.' The relations these respondents have are not always equal—some communities are strictly hierarchical. The phrase 'to be at service' consists of a submission of the respondent to the community.

Just as life stories can be compared with respect to the salience of the theme agency versus communion, they can also be contrasted in terms of the theme of redemption versus contamination (McAdams 2001). The redemption sequence is the extent to which the participant is able to transform or redeem bad scenes into good outcomes. The contrasting narrative form of the redemption sequence is the contamination sequence, wherein positive scenes transform into bad or negative outcomes (McAdams 2001). The idea of redemption is highly visible in the stories of the respondents who experienced an illness or a near-death experience. These events were eventually seen by them as the turning point, which led to the positive outcome of becoming a shaman or a shamanic practitioner. In their weakened state, these respondents were visited by the spirits who gave them the option to live or to choose this path; therefore, this illness or breakdown was seen as a preparatory state. The contrasting sequence, contamination, was surprisingly invisible in these responses.

One of the major characteristics of well-formed life stories is assigning a strong sense of meaning to one's experiences and oneself. This narrative characteristic has been defined by researchers as meaning-making, the way that the participant gleans messages or meaning from an event (McLean and Pratt 2006). Meaning-making is mostly found in narratives that contain any kind of conflicting or tension-filled events, as crises or vulnerabilities tend to be particularly important for meaning-making. Unsurprisingly, meaning-making was found in the stories of the respondents who experienced a form of vulnerability due to a nervous breakdown or a disorder. The category of meaning-making therefore highly corresponds to the category of redemption found in these answers. Respondent 24 was 'born with very [bad] sight' and stated that she would sing 'to spaces to discover where [she] was. This helped me to navigate the world, but it also showed what wasn't there.' This eventually led to 'using [her] voice as ultrasound', a skill she continues to use with clients. Similarly, Respondent 88 'had a nervous breakdown and had entered the spirit world, not knowing how to come back, very psychologically open in many dimensions and not knowing what was reality and what was illusion/delusion. It was very frightening at the time. [He] didn't understand what was happening.' Later, this event was described in one of the answers as the respondent's initiation by the spirits. 
Autobiographical reasoning is the process of making inferences about who a person is and what their life means. This can vary from identifying lessons learned to insights gained in life experiences. It is the activity of creating relations between the past, present, and future life, and one's personality and development, marking this development or growth through sequences of scenes (McAdams and Manczak 2015; Adler 2012). This category was not present in all the respondents' answers, but some mentioned that their personality or life had changed because of their experience with shamanism. They either felt more 'of service' or 'more at peace with [themselves]'. Nonetheless, not all of the respondents felt that their life or personality had changed, but they did mention that 'this [had] always been [their] life' and it had 'realigned [them] to [their] work over many lives'; 'it was a continuation of many things [they were] already doing.' The latter is still an understanding of or insight into the meaning of their life.

The last two categories, exploratory narrative processing and coherent positive solution, were not visible at all or only to a limited degree. The exploratory narrative processing refers to the extent of self-exploration evident in the answers, a development process that enriches narrative identity over time (Pals 2006). None of the answers consisted of any kind of exploratory narrative processing. The coherent positive solution, however, was apparent in the answers of two respondents: Respondent 24 who declared to be 'at service' and Respondent 88 who mentioned '[they] had been prepared the whole time.' These two respondents were also the people who elaborated on their story most extensively. They gave the most detailed answers to the questions, and their responses came closest to a proper narrative-bibliographical life story interview.

After analyzing these responses using the narrative construction model, we can identify some clear patterns: considering the respondents who experienced some kind of crisis in their youth - Respondent 24, Respondent 40 and Respondent 88-there is a clear pattern in the way they experience agency and communion. These respondents experienced something, overcame it, and now consider themselves at service to the community by having close contact with the spirits. They consider themselves as individuals having their own agency, but also as part of a broader community or a larger organism. It seems that a strict dualism between individualism versus collectivism or community does not apply. For these respondents, both elements of apprenticeship of neo-shamanism and traditional shamanism are combined. Neo-shamanism is an individual phenomenon involving the use of altered states of consciousness and the engagement of other life forms for the purpose of self-healing and finding the true, authentic self (Adler 1979). Neo-shamanism lacks the social role and purpose of traditional shamanism (Townsend 2005). Although the respondents do feel part of a broader community, they do not comprehend the same social role as within traditional shamanism. Their community is much vaguer and less defined, and can be anything other than themselves. This is also the reason why these respondents found it necessary to conduct the non-profitable part of their work. Some stated clearly that they do not charge for helping others, as shamanism is a gift which they were given to help others.

When asked to describe whether they have had any kind of initiation, all respondents traced this initiation to another kind of authority: either to the spirits or another shaman.

In other words, the community authorizes the initiation and this is similar to traditional shamanism in which recognition by the community plays a very important part in combination with approval of the spirits. In traditional shamanism, like Singh explains, a person does not find shamanism on their own, and the whole recognition of a person as a shaman, both the start of the apprenticeship and the initiation is often social (Singh 2018). A person is recognized as a potential shaman by the community, mostly by some kind of marker that identifies the individual as capable of becoming a shaman (Singh 2018). When the respondents were asked to describe how they found shamanism or how shamanism found them the answers differed from: 'Quite by accident, had a serious illness and it began there' (R40) to 'Tibetan master who was my Vajrayana Buddhist master'(R18). This indicates that some respondents were introduced by another authority while others identified themselves as potential shamans after they experienced self-concluded spiritual markers, such as after suffering from a serious illness or a near-death experience. The respondents, who were spiritually initiated or 
introduced, had a much higher degree of redemption sequence and meaning making. This resonates more with the self-agency and individualism found in neo-shamanism than the kind of individualism found in traditional shamanism (Friedman 1992).

\subsection{Contemporary Narratives_Images and Identities: Which Shaman Do You Mean?}

As a second method of analysis, we compared Mayer's attributions of a shaman model to the responses of our respondents. The shaman, as we have seen from the previous parts of this article, is a complex and contested figure in modern society, a focal point of increasing interest in today's spiritual landscape. However, what precisely a shaman is, how one becomes one and what one 'does' as a shaman is rather diverse and depends on different cultural perspectives in a traditional sense. Traditional forms of shamanism may have an influence on how contemporary shamans think about themselves and their practices. However, neo-shamanism might also come into play, as one of the available options.

Mayer's approach to making sense of this diversity is to identify ten elements of the 'shaman myth which form the popular image of shamanism in Western societies' (Mayer 2008, p. 70). These ten elements are considered by Mayer as attributions, based on 'handed down knowledge on traditional shamans' (Mayer 2008, p. 71) which are related to a 'Western, inevitably fragmented, perspective' (idem). They are: (1) the healer, where a holistic view of the human focuses on recreating the balance by keeping the 'social context, the ancestors, the natural environment as well as the cosmos' (Mayer 2008, p. 71) in mind; (2) the master of ecstasy, where, roughly following Eliade's ideas, Mayer identifies the centrality of the promise of an intense experience where the shaman remains 'master' by using his will; (3) the 'wanderer between the worlds', where the access to extraordinary aspects of reality is central-a person acting with intent, crossing borders and belonging to several cultures and reality realms; (4) the magician with exceptional skills such as weather-making, divination, psychokinesis, telepathy and miraculous healing based on 'self-sacrificial readiness-to-suffer and highly determined attitude'; (5) the master of metamorphosis into different roles and different entities; (6) the interpreter of the world, who understands omens, talks to different entities and nature-having insight into the way things are connected, and thus able to unravel structures of meaning; (7) the respected outsider, the anarchist who sees beyond the surface of things and stays in tune with a deeper and more important reality, standing up for true authenticity; (8) the ecologist with access to ancient, traditional knowledge which sees nature as an archaic power and reminds others of a past when harmony between humans and nature was the norm; (9) the 'exponent of a non-materialistic cosmology', where causality is different, and thus scientific thought is shown as limited; (10) the exponent of an 'alternative, individualistic spirituality' which is anti-hierarchical, where spiritual helpers and guides are personal, 'found' and 'owned', while the divine principle to which the shaman is subordinated remains abstract (Mayer 2008, pp. 84-86). Our question is whether and in what way these attributes are present in the narratives of the respondents which identified themselves as shamans?

For this purpose, we chose to look at the responses of respondents as a whole. Narratives from individual respondents are enlightening through the amount of detail they contain. From the 14 respondents discussed in this article, five respondents have answered the questionnaire's questions in such a detailed way that their answers form a well-formed narrative.

Respondent 1's story is well-structured, full of detail and chronological in order. This narrative describes the path of life between childhood and present age, highlighting the most important moments, which are worth mentioning with regard to the topic of the survey, shamanism: becoming aware of spirits at the age of 15 , when the process of receiving teachings from the spirits starts, complemented at 27 by human teachers. This is highlighted by the respondent as an 'ongoing' process which underlines the feeling that 'this has always been my life' seen from the perspective of 60 years. This ongoing process is not something that happens to the respondent, but it completely frames one's experience of life in the sense that it becomes life itself ('it is my life'). In this account, we also learn that the respondent considers shamanism as 'work' and does this in a 'fairly traditional' way, following what 
he calls the 'Mongolian/Central Asian way'. In this respect, training and initiation is strengthened by 'traditional Mongolian friends' and by the use of (authentic) ritual objects from these traditions. These objects are used according to initiation and teachings which target their specific use. An initiation into shamanhood has been received directly from the spirits 'incrementally over the years'.

In terms of Mayer's attributions, in Respondent 1's narrative, we encounter a tendency towards being a respected outsider (7). The respondent identifies human and non-human friends and also takes distance from forms of shamanism that one does not identify with 'I don't practice core or new age shamanism, which are very common in the west', showing a certain degree of anarchy with respect to the 'west' - this alternative reality of the spirit world which is confirmed by friends belonging to another culture as authentic and 'traditional'. This respondent also acts as an interpreter (6) through the use of objects from different cultures, seeming to reveal deeper structures of meaning beyond culture, which are taught by and allowed access to by the 'spirits'. In this sense, the respondent is also a wanderer between worlds (3), human worlds of different cultures and worlds of spirits. An aspect which seems central to the narrative of this respondent but is not captured by Mayer's attributions is that of apprenticeship and hierarchical subordination to the spirits - this seems to be a narrative of agency willingly given up.

Respondent 24's story is also chronological and emphasizes the circumstances before the respondent was visited by spirits and the unique skills this respondent acquired both before and due to these visits. Relating and navigating through space are made by the respondent through song as one cannot rely on one sense of sight. Singing was used also to 'learn' in 'darkness', and this is where spirits start to visit. The precise moment in life when this happened is unclear, but it can be placed with certainty before the age of 20, when a severe and almost fatal illness made the spirits return and offer a deal: keeping one's life in exchange for 'work with them'. The respondent actively chooses life and spirits 'taught'. Initiation takes place after this 'long illness', with one's 'mistress spirit' coming into the respondent and embodying herself for a timespan of two hours. This process of entering is then 'moderated' by the respondent, in the sense of learning to gain more control over it. The skills and activities that the respondent mentions concern 'discover what is displaced' with the help of 'ancestral and land spirits', healing through 'embodying spirits who do the healing' and ancestral fragmentation. As a skill, singing 'spontaneously all the time' is seen as important by the respondent. The respondent has been training with a 'Scandinavian school' and was part of a peer group for a longer time. In general, the most important dimension is that of being of 'service, rather than just here for myself', which articulates both the importance of forms of community and a certain role within them.

In terms of Mayer's attributions, in Respondent 24's narrative, we encounter a tendency towards identification as a healer (1) of others and a 'mild' magician (4), who uses the power of one's voice 'as ultrasound' for unexpected purposes. This respondent also speaks of 'embodying spirits who do the healing' thus making a link between the attributions of being a master of metamorphosis (5) where one embodies and transforms into different entities and the process of healing (1), which is the main activity of this respondent. Here also, 'ancestral and land spirits direct' the respondent to be of 'service'-however, the will of this respondent is trained through the years to gain control of the (length of the) process of possession ('I began to learn how to moderate the incoming'), which resembles Mayer's master of ecstasy (2) attribution.

Respondent $88^{\prime}$ s story is also chronological in order but also uses one narrative in order to illustrate a more general point, which is made in the beginning: 'I believe people are born shamans and that you cannot become one'. The historical narrative begins at the age of 20, with exploration and a sense of being 'gifted' and continues with the 'conspiration' of spirits to give an initiation at 22. This takes place through a nervous breakdown in which the 'spirit world' is entered, from which the respondent does not know how to come back. The respondent described this experience as 'very frightening' as one was 'psychically open' and 'not knowing what was reality and what was illusion/delusion'. A diagnosis of schizophrenia kept the respondent wanting to become 'normal' for 7 years, 'ignoring' being 'unwell' (emphasis of the respondent) and now understanding 'the concept of shamanic sickness'. 
This changed upon meeting the 'medicine path', which 'makes sense' and also brings back memories of past lives 'having walked this path'. Self-healing is done through the use of sacred plants or sacred medicine (Ayahuasca and San Pedro are mentioned). Along with the realization and memory of being a shaman, the respondent moves from a position of self-healing to that of a healer, leading ceremonies. In retrospect, personal difficulties are seen as 'being prepared' to 'navigate the different realms', although this 'path' was never imagined and was 'not easy to accept'. The relationship with spirits is complex and not necessarily hierarchical; the respondent listens to, barters with and trusts spirits 'even when you don't understand'. Being a shaman is not a 'joke, hoax or a game', one knows it is at one's 'core' and not an 'easy path'. The skills the respondent uses are the 'traditional medicines $\ldots$, following the cycles of nature and connecting with the elements' and having most of the time ' 1 foot in the spirit world'.

In terms of Mayer's attributions, in Respondent 88's narrative we encounter a tendency towards identification as 'exponent of a non-materialistic cosmology' (9), where medical science and its diagnosis of schizophrenia are seen as incomplete and inadequate in establishing the root, cause and use of one's problems. When a different form of causality is encountered, when the respondent 'came across the medicine path', 'everything started to make sense' as the respondent was 'already gifted' and going through a 'shamanic sickness'. This makes the respondent a wanderer between 'different realms' (3), between the worlds of here and now and the medicine path, with the help of sacred plants but also across time and space, through remembering 'many lifetimes in various parts of the Americas but mostly southern United States'. Being a healer (1) starts with healing the ' $I$ ', and according to this respondent it also seems to stop there. Although the respondent leads 'sacred medicine ceremonies', the goal is not to heal others but rather to use medicines, follow nature and the cycles of elements by keeping the balance (1). Having ' 1 foot in the spirit world' points to a continuous access to a different, alternative part of reality (3), where the respondent listens to, barters with and trusts 'the spirits'. Most importantly, Respondent 88 states 'if you want to become a shaman then you are probably not one', referring to the difficult 'path' one has to walk.

Respondent 143's story is less complete, and it also does not necessarily follow a historical linearity. Important moments identified are receiving oracle cards, joining a friend who was taught shamanism, going to a clairvoyant and receiving different types of (not necessarily shamanic) training. The message received from the clairvoyant is described in the most detail, in the vision the respondent is identified as 'being with' a person undergoing a death process which is connected to journeying and a 'psychopomp event'. The respondent can 'journey to people and give them healing'. Skills involve working for a 'power animal', which brings 'rich rewards'. The path of being a shaman is experienced as a 'continuation of many things I was already doing'.

In terms of Mayer's attributions, in respondent 143's narrative, we encounter a tendency towards identification with wandering between the worlds (3), as the emphasis on the psychopomp experience shows. For this respondent, journeying seems to be the most important experience and tool. Working for 'power animals' connects to being an interpreter (6), however, the relationship implied in the respondents answer implies not a neutral stance, as proposed in Mayer's category, but rather a hierarchical subordination to other entities which are not clearly named.

Respondent 154 's story also follows a historical build-up, with an unclear starting point in time centered around the experience of 'odd things' such as trembling hands and visions experienced by massage clients. 'Coming home' is experienced during a sweat lodge ceremony and is followed and strengthened by training with 'allies' which 'had been waiting'. 'Fully committing' is reached upon the loss of one's job and is mentioned in relation to a course on core shamanism and a voice saying, 'now it is time'. Training was followed for a period of 15 years. The skills listed in this account were 'communicating with my allies, listening, journeying, being a channel for healing for others', which is made possible by having 'found my song for healing' and a different way of seeing nature. Healing is the most important task to be performed in this case. 
In terms of Mayer's attributions, in Respondent 154's narrative, we encounter a tendency towards identification with a master of metamorphosis (5), changing roles and entities and other 'odd things' which started to be reported to the respondent by others - here, there seems to be less agency in the metamorphosis than Mayer's category suggests. Journeying, communicating with allies and being a channel are all important aspects for this respondent, which resembles Mayer's categories of wanderer between the worlds (3), interpreter who also has a changed relationship to nature (6), and again as a master of metamorphosis (5). The most important goal is the 'healing for others' for which tools such as 'my song' are used, which falls under Mayer's healer category (1).

Comparing the responses of respondents among themselves, we can observe that the attribution most often used is that of being a psychonaut and 'wanderer between the worlds' (3), followed closely by the attributions of healer (1) and interpreter of the world (6). Next in line are the attributions of master of metamorphosis (5), and finally the master of ecstasy (2) respected outsider (7) and an exponent of non-dualistic cosmology (9) attributions. The attributions not mentioned by our respondents are those of an ecologist (8) and exponent of an alternative, individualistic spirituality (10). If we compare these attributions to the way the same characteristics are described in the literature about shamanism and neo-shamanism, we can see that the most used attributions of the wanderer (3), healer (1) and interpreter (6) are also categories which are central to the literature about traditional shamanism. Numerous accounts focus on the travels, journeys, movements and the skills needed for shamans in order to move between, to wander between different worlds, different realms of existence (Eliade 1964; Blain 2003). This ability to wander between realms also remains central in neo-shamanic accounts, although the 'methods' and 'techniques' used are therefore different, and are often learned from different sources, making use of tools from more than one shamanic tradition. Among the diverse tasks taken up by traditional shamans, that of healing is mentioned as one of the most important. Especially in neo-shamanism, the importance of healing increases, making it central both for the self and also possible for others. The attribution of being an interpreter has a different connotation in the literature concerning traditional shamans, where the shaman translates foremost between humans and spirits, for the benefit of the community. Our respondents interpret between cultures, using objects and artefacts from different settings, which are being taught and allowed access to by spirits (Respondent 1 ). They also interpret among helpers or allies and spirits, where interpretation is connected to the ability to understand and act upon their wishes (respondent 143). Interpreting the languages of different realms, translating messages from 'beyond' into action (respondent 154) also takes place. Surprisingly, although individualism seems to be mentioned as one of the foremost characteristics of neo-shamanism and one of its main differences from traditional shamanism, Mayer's shaman as an exponent of an alternative, individualistic spirituality (10) is not found in our accounts.

\section{Shamans and Contemporary Narratives: Do We Need a New Compass?}

Looking at our respondents' responses with the help of our two methods of analysis has highlighted a few typical ways of constructing a narrative, some important tropes present in their narratives and emphases placed on different roles and visions of what a shaman is and is meant to be.

First of all, we can notice that agency, its loss, regain and mastery are prominent in all accounts. In this sense, people's narratives focus on reinterpreting earlier struggles. We can observe a rather linear way of talking about agency by all our respondents. Temporarily, we start from a point when individuals lose their agency due to forces outside of themselves, either through sickness, an initial (unpleasant or misunderstood) visit from the spirit s or an unexpected event in their life. This initial moment is connected strongly to a first experience that fundamentally changes something in the respondents' knowledge, perception or sometimes in their life circumstances. This initial experience can be temporarily short or long, and it is perceived as very intense and transformative. In some cases, fellow humans are involved as 'guides' of sorts, which mostly involuntarily point the attention of the respondent towards different possibilities than the ones available to them beforehand. For most 
respondents, there seems to be a sort of breakthrough taking place, which offers a solution to, or respite from, problems, difficult situations or trials of some sort which have been experienced.

In the shamanic literature, this is marked as the moment of introduction. In the accounts of our respondents, this is simultaneous with a first experience of change. No recognition of signs by others is mentioned, as is often the case in the literature on traditional forms of shamanism. This does not mean that the signs are not present or visible, but rather that they are interpreted differently in other cultural systems. Respondent 88 mentions being diagnosed with schizophrenia, which he later recognizes as shamanic illness. Reading the signs is culture-dependent and pre-supposes a shared culture; signs translate to symptoms which can be read through medical knowledge in the modern world. As most forms of shamanism are not local forms of knowledge in the western context, they are also not recognized as such. We suspect this is one of the reasons why recognition as a shaman by the community is also not mentioned as important for our respondents.

The second moment or phase regarding agency in narratives is the regaining of one's power to act, which is based on a reappraisal of one's identity, a new sense of self which, in all accounts, is connected to the realization of being or being on the path of becoming a shaman. This is when most respondents heal, either physically or psychologically, the previous situation that is characterized by a loss of their power or will to act. They learn to deal with hardship, learn to diminish or control the force of spirits, recognize events or entities for what they truly are (thus, things are also placed in a different perspective). This phase includes, on the one hand, an acceptance of oneself and one's powers and limitations, but also a radical reappraisal of one's relationship to those around them: the human and beyond-human community. This reappraisal of the self comes with a new understanding of one's role in relationship to forces such as spirits, humans, plants, nature, animals but also a generic and abstract humanity. A change also takes place in the relationship between one's individual and collective past, present and future, and also between different territories, lands, realms and cultures, which are not considered as distinct from each other, but rather as complete parts of a coherent and harmonious whole. This is the moment where one recognizes oneself as a shaman, or starts to understand one's previous life situations as trials and one's relationship to other kinds of entities as shamanistic.

This phase of becoming a shaman is identified in the literature as the moment of initiation. In the literature on traditional forms of shamanism, this moment is unpleasant, even dangerous, and a matter of life and death to the shamans to be. In the accounts of our respondents, the initiation seems to be a cognitive shift induced by an unusual but not truly unpleasant experience. Here, too, the emphasis is placed on the experience and the shift experienced because of it. The experience centers around a reappraisal of one's own position in a complex universe populated by different beings, followed by a re-evaluation of one's tasks and role in relationship to self, human and non-human others and also society and nature. Space and time gain different meaning and connections, among which those of the shaman are seen as crucial. This shift resembles the process of self-actualization described by Noll (1989) and the attainment of spiritual values resembling enlightenment which are sought by using shamanism as a method (Znamenski 2007).

The third moment or phase regarding agency is that of mastery. Interestingly, here, the agency of the individual in all accounts decreases once more, as the self bends at the will of the spirits for the purpose of work for others, as 'being of service' is what is being done. This position is a consequence of the reappraisal of one's own position with regard to spirits, fellow humans and larger contexts, such as nature. Simultaneously, this is the time when the respondents begin to learn to use the 'doing' of being a shaman, becoming masters of their own trade by applying the things learned, mostly from the spirits, in practice.

This, in the literature, comes close to the final goal of being a shaman. Remarkably, the accounts of our respondents here remind us of the traditional shamanism literature where the ultimate goal is to serve the community of people by acting as a mediator between the spirits and humans. Despite contemporary shamans not being recognized by a community and also not operating in relatively small, tight and stable groups of people, the need for community and acting for more than the self is 
still expressed by most contemporary shamans. Although it seems that the part of becoming a shaman is walked through developing the self, this is not the ultimate goal of the process. Instead, it is service for the community and 'work' for the spirits that is articulated.

As agency undergoes a recognizable dynamic through the process of becoming a shaman, the same can be said about the dynamic of authority. In all accounts, we see the clear authority that entities mentioned as spirits, allies and helpers, which appear in the form of plants and animals, have over the persons becoming shamans. Indeed, shamans seem to subordinate themselves both to their allies and to spirits. No human authorities are mentioned, and no human teachers are placed in a position higher than oneself. Humans are always mentioned in the role of peers. There is a lack of clarity about the identity of the spirits. We notice some reluctance in individual accounts when speaking out on this topic.

In the literature, human and non-human authority are mentioned to the same degree and with the same importance, especially in relation to apprenticeship. Lewis (2003) mentions the importance of human and spirit teachers equally, as two different equally important stages in the process of becoming a shaman. However, in these accounts, after the introduction and both before and after the initiation, spirits seem to have the utmost authority, to which humans are unmatched.

Regarding the topic of community, respondents mention an abstract sense of 'we' ('we are all connected' R71) regarding fellow humans, along with a smaller group of 'clients' who come to be helped by the shaman. As a relationship with a human teacher is not mentioned, fellow humans are only indirectly and impersonally important in the process of learning, through an introduction to shamanism, through their books—-here, Eliade's influence could be mentioned again—or in the context of workshops. Peers are discussed in responses to two different questions (Q12 and Q13): one during the discussion on the similarities with peers, the other on the differences between the practitioner and fellow shamans. Here, it is interesting to note that most respondents answer both questions in terms of differences, highlighting the ways they are different from or unique among other (western) practitioners, and how they follow traditional ways, indigenous lineages. 'Core shamanism' and new age shamanism are mentioned in a depreciative way. Only the ability to offer healing and the use of ritual objects are mentioned among the things that are similar between the respondents and their peer group.

In the literature, this is mentioned as neo-shamanisms' use of traditions as a way to acquire legitimacy (Lindquist 1997). Here, we also see an emphasis on the 'techniques' of shamanism as being highlighted, which corresponds to Eliade's (1964) ideas of cultural translations of transcultural motifs and techniques, although the connection with ecstasy is only loosely present for our respondents.

Concerning becoming a shaman, our respondents talk about always knowing, or having a sense that something was different for them, that they were spiritual or 'mystic' from a young age onwards. While this difference did not make sense at first, it becomes meaningful after their first encounter with shamanism. Learning about shamanism does not happen in a structured way: it seems to be based on choices of the respondents themselves about how and what they do to learn, except when they are being taught by spirits. Apprenticeship in our accounts is substituted by learning, and the relationship of teacher-student between humans is replaced by learning independently or being taught directly by spirits, with inspiration coming at times from fellow humans. Hardship seems to end with recognition, which emerges in almost all cases after meeting shamanism. Trials stop when one regains one's agency, which, as discussed before, is connected to the moment of becoming a shaman. The moment of becoming a shaman is experienced by most respondents as easing up on the unfavorable or confusing conditions met before knowing about shamanism, and is not mentioned as outstandingly difficult. Recognition as a shaman for our respondents is mostly made by the self and only at times by spirits.

In the literature, we see signs being mentioned, signs which signal to others that one has the capacity to become or possibility of becoming a shaman. These signs are not certainties but indeed, possibilities. Moreover, these signs are not necessarily recognized by oneself, but are meaningful in a social setting, in a cultural context which can interpret these signs. This is directly related to apprenticeship in traditional becoming models, where signs are taken upon as a beginning of an apprenticeship with a human teacher, which also is connected to a period of hardship. These hardships 
mostly continue throughout a shaman's full life, according to the literature on traditional shamanism, with initiation being an outstandingly difficult process. Recognition in a traditional sense is a very important step on the path of becoming a shaman. There is recognition and acceptance from the spirits, but the literature highlights the central importance of social recognition: of accepting the skills and due services of a shaman within one's community. This last dimension is not present in our data; self-recognition is paramount for our respondents.

Regarding extraordinary powers, only one of our respondents mentions the ability of using sound as a radar. Besides being in communication with spirits, which respondents see as a way to properly see and engage with reality, no other 'extraordinary' capacities are mentioned. Ecstasy as a modality of engaging with reality is only mentioned explicitly by one of our respondents. Although ecstasy seems to play an important role in both the literature on traditional and neo-shamanism (which we believe points out the influence of Eliade's work on both bodies of literature), we find little evidence of it in our data.

Moving between realms, journeying remains an important trope, although the respondents give little information about the realms themselves. This is similar to the way sharing about spirits as entities is treated by our respondents. According to our respondents, the function of the journeys to the other realms is to gather knowledge and bring healing.

In the literature, one of the important functions of travelling, journeying between realms is to guide the spirits of the dead members of the community to the right places. This function of psychopomp is only mentioned once by one of our respondents, although differently than one might suspect. The psychopomp experience is described by the respondent in a passive way, whereby the psychopomp event was told to the respondent by a clairvoyant. Therefore, in this case the psychopomp had already taken place while the respondent did not know about it until the clairvoyant told her. The other respondents do not mention any psychopomp event at all.

\section{Conclusions}

Characteristics which are central to becoming and being a shaman are mentioned by the literature discussing shamans and so-called neo-shamans. When we reflect on these by using our respondents' accounts, all contemporary shamans based in the UK, we notice that most of the mentioned characteristics and patterns do not fit neatly. Some characteristics from both bodies of literature are overrepresented, while others are barely, if at all, mentioned.

We would like to highlight our finding concerning the role of the community in becoming and being a shaman. From the narratives analyzed, we saw that recognizing themselves as shaman is paramount for our respondents, although wanting to become a shaman is seen as a clear deficiency in actually becoming one. While, for contemporary shamans, initial signs go unnoticed or are misinterpreted by others and recognition as a shaman is an individual affair, service to the community in a larger and more abstract sense than traditional shamanism allows remains central. In our interpretation, this means a separation of modern shamanism from the specificity of exclusive local cultures and a turn towards a larger and more encompassing idea of humanity, in which the shaman can then be of service. We can speak of the individualization of the process of becoming a shaman, but that does not make modern shamanism individual. This turn is not surprising given the influence of Eliade's legacy in emphasizing the universalism and primordiality of shamanism itself and the important role of writers such as Harner (2009) in spreading interpretations of shamanism, which highlight a need for the recovery of 'archaic' knowledge for the benefit of contemporary society. In this line of thought, while shamanism itself is universal and 'archaic', universal social change can take place only through individual transformation (Znamenski 2007, p. 257; see also Lindquist 2005). Western practitioners of shamanism are experimenting with local traditions, but at the same time refer to the universal nature of shamanic practices, as one of our reviewers has pointed out. They also engage with a broad idea of humanity which goes beyond such universalism and resembles modern forms of spirituality (Heelas and Woodhead 2005). 
Looking at the powers a shaman develops, learns and then uses, we see a turn towards an increase, if not exclusivity, in the role of spirits. While shamans seem to learn less from human teachers, their connection to allies and spirits is hierarchical and based on obeisance. Shamans do not express any doubts with regards to the identity or wishes of their spirits. However, for us, it remains unclear who these spirits are and if our respondents are referring to the same of different entities. The powers the shamans in our sample mention seem less extraordinary then those mentioned in the literature. Do respondents refrain from speaking about such things, or is this something that they do not experience? In any case, we see a turn towards non-human forms of authority both while becoming and being a shaman. This is also the first way in which modern shamans claim authenticity: through direct connection and subordination to the spirits. They seem to lose agency, but gain authenticity, through this way of relating.

Much highlighted by our respondents is the difference between themselves and other practitioners. Unique characteristics and divergences, made on the basis of differences among different traditions and references to unbroken lines of initiation, are highlighted. In this sense, our respondents try to connect to traditional forms of shamanism and claim their legitimacy. This can be seen as a second way of claiming authenticity.

We rarely heard anything about who or what spirits are, the importance of ecstasy and the psychopomp role of the shaman. The results presented in this paper are limited by the particular sample used, and a more thorough discussion of the results could be enhanced through adding contextual factors as variables within the discussion. We cannot say, based on our material, what the reason behind this could be. If these specific aspects of shamanism are changing in content or importance is as yet unclear, and more research is needed to answer. For this reason, research on contemporary shamanism must not be limited by the supposed divergence between traditional shamanism and neo-shamanism. Instead, contemporary shamanism must be understood as a widespread, manifold and multifaceted phenomenon, which is not as different from traditional forms of shamanism as one might suspect. To this end, studying narratives of personal experience adds invaluable insights.

Author Contributions: Conceptualization, C.I. and S.B.; Theoretical background, C.I.; Methodology, C.I. and S.B.; Data collection, C.I.; Data curation, S.B.; Formal analysis, C.I. and S.B.; Writing-original draft, C.I. and S.B.; Writing-review and editing, C.I. and S.B. All authors have read and agreed to the published version of the manuscript.

Funding: This research received no external funding.

Acknowledgments: The authors thank the anonymous reviewers for the insightful comments.

Conflicts of Interest: The authors declare no conflict of interest.

\section{Appendix A}

Overview of survey questions used for this article (essay question EQ; multiple choice question MCQ which included the option 'other:'):

Q3. Can I ask you to describe how you found shamanism/ how shamanism found you? (EQ)

Q4. What kind of knowledge/skills would make you a shaman if you do not consider yourself already one? Which knowledge/skill matters for you the most if you are already a shaman? (EQ)

Q6. Did you receive a formal education as a shaman? For how long were you trained? (EQ)

Q8. Did you receive an initiation? If so, what kind of initiation? Was it a performed ritual, by another shaman, or did the initiation occur in another way? (EQ)

Q9. In what way has your interest in shamanism changed you (if applicable)? (EQ)

Q12. What are the similarities between you and other shamans/practitioners of shamanism? (EQ)

Q13. What are the differences between you and others shamans/practitioners of shamanism? (EQ)

Q38. What is your age? (MCQ)

Q39. What is your gender? (MCQ)

Q40. What is the highest degree or level of school you have completed? If currently enrolled, highest degree received. (MCQ) 
Q42. Do you live in ... (MCQ)

\section{References}

Achterberg, Jeanne. 2002. Imagery in Healing: Shamanism and Modern Medicine. Boulder: Shambhala Publications. ISBN 9781570629341.

Adler, Margot. 1979. Drawing Down the Moon: The Resurgence of Paganism in America. New York: The Viking Press.

Adler, Jonathan. 2012. Living into the story: Agency and coherence in a longitudinal study of narrative identity development and mental health over the course of psychotherapy. Journal of Personality and Social Psychology 102: 367-89. [CrossRef] [PubMed]

Atkinson, Jane. 1992. Shamanisms today. Annual Review of Anthropology 21: 307-30. [CrossRef]

Bernstein, Anya. 2008. Remapping sacred landscapes: Shamanic tourism and cultural production on the Olkhon Island. Sibirica 7: 23-46. [CrossRef]

Birx, ed. 2005. Encyclopedia of Anthropology: Five-Volume Set. Thousand Oaks: Sage Publications, vol. 1. ISBN 100761930299.

Blain, Jenny. 2003. Nine worlds of Seid-Magic: Ecstasy and Neo-Shamanism in North European Paganism. London: Routledge. ISBN 9780415256513.

Blain, Jenny, and Robert Wallis. 2000. The 'Ergi' Seidman: Contestations of Gender, Shamanism and Sexuality in Northern Religion Past and Present. Journal of Contemporary Religion 15: 395-411. [CrossRef]

Boekhoven, Jeroen. 2013. Public Individualism in Contemporary Dutch Shamanism. In Religion Beyond Its Private Role in Modern Society. Edited by Wim Hofstee and Arie van der Kooij. Leiden: Brill, vol. 20, pp. $245-57$. ISBN 978-90-04-25784-9.

Burkett, Tim. 2005. A psychological inquiry into neoshamanic practice. Revision 27: 3-8. [CrossRef]

Clifton, Chas S. 1994. Shamanism and Witchcraft. St. Paul: Llewellyn Publications. ISBN 1567181503.

Coleman, Eli, Philip Colgan, and Louis Gooren. 1992. Male cross-gender behavior in Myanmar (Burma): A description of the acault. Archives of Sexual Behavior 21: 313-21. [CrossRef]

Comaroff, John, and Jean Comaroff. 2009. Ethnicity, Inc. Chicago: University of Chicago Press. [CrossRef]

Davidov, Veronica. 2010. Shamans and shams: The discursive effects of ethnotourism in Ecuador. The Journal of Latin American and Caribbean Anthropology 15: 387-410. [CrossRef]

De Heusch, Luc. 1981. Nouveaux regards sur la royauté sacrée. Anthropologie et Sociétés 5: 65-84. [CrossRef]

Diószegi, Vilmos. 1960. Sámánok nyomában Szibéria földjén: Egy néprajzi kutatóút története. Budapest: Magvető Könyvkiadó.

DuBois, Thomas. 2011. Trends in contemporary research on shamanism. Numen 58: 100-128. [CrossRef]

Eliade, Mircea. 1964. Shamanism: Archaic Techniques of Ecstasy, etc. London: Routledge \& Kegan Paul. ISBN 100140191550.

Elliott, Jane. 2005. Using Narrative in Social Research: Qualitative and Quantitative Approaches. London: Sage Publications, Inc. ISBN 1-4129 00409.

Farahmand, Manéli, and Sybille Rouiller. 2016. Mobility and religious diversity in indigenousness-seeking movements: A comparative case study between France and Mexico. Religion and Superdiversity 18: 53-71.

Freeman, Carla. 2011. Embodying and affecting neoliberalism. A Companion to the Anthropologyof the Body and Embodiment, 353-69. [CrossRef]

Friedman, Jonathan. 1992. The past in the future: History and the politics of identity. American Anthropologist 94 : 837-59. [CrossRef]

Geertz, Clifford. 1973. Thick Description: Toward an Interpretive Theory of Culture. In The Interpretation of Cultures. Edited by Clifford Geertz. New York: Basic Books, pp. 3-30. ISBN 100465093558.

Handelman, Don. 1967. The development of a Washo shaman. Ethnology 6: 444-64. [CrossRef]

Harner, Michael. 2009. The Way of the Shaman: The Definitive Handbook. New York: HarperOne. ISBN 0061800252.

Heelas, Paul, and Linda Woodhead. 2005. The Spiritual Revolution. Why Religion Is Giving Way to Spirituality. Oxford: Blackwell. ISBN 1405119586.

Hinchman, Lewis, and Sandra Hinchman. 1997. Introduction. In Memory, Identity, Community: The Idea of Narrative in the Human Sciences. Edited by Lewis Hinchman and Sandra Hinchman. New York: State University of New York, pp. xiii-xxxii. ISBN 0791433242.

Holmberg, David. 1983. Shamanic soundings: Femaleness in the Tamang ritual structure. Signs: Journal of Women in Culture and Society 9: 40-58. [CrossRef] 
Hutton, Ronald. 2007. Shamans: Siberian Spirituality and the Western Imagination. London: Hambledon Continuum. ISBN 9780826446374.

Ingerman, Sandra, and Hank Wesselman. 2010. Awakening to the Spirit World: The Shamanic Path of Direct Revelation. Louisville: Sounds True Inc. ISBN 1591797500.

Lebra, William. 1966. Okinawan Religion: Belief, Ritual and Social Structure. Honolulu: University of Hawaii Press. [CrossRef]

Lenski, Gerhard. 2013. Power and Privilege: A Theory of Social Stratification. Chapel Hill: University of North Carolina Press. ISBN 0807841196.

Levin, Theodore. 2019. Where Rivers and Mountains Sing: Sound, Music, and Nomadism in Tuva and Beyond. Bloomington: Indiana University Press. ISBN 0-253-34715-7.

Lewis, Ioan. 1989. South of North: Shamanism in Africa: A Neglected Theme. Paideuma: Mitteilungen zur Kulturkunde 35: 181-88.

Lewis, Ioan. 2003. Trance, possession, shamanism and sex. Anthropology of Consciousness 14: 20-39. [CrossRef]

Lindquist, Galina. 1997. Shamanic Performances on the Urban Scene: Neo-Shamanism in Contemporary Sweden. Ph.D. dissertation, Stockholm University, Stockholm, Sweden.

Lindquist, Galina. 2005. Healers, leaders and entrepreneurs: Shamanic revival in southern Siberia. Culture and Religion 6: 263-85. [CrossRef]

Mayer, Gerhard. 2008. The Figure of the Shaman as a Modern Myth: Some Reflections on the Attractiveness of Shamanism in Modern Societies. Pomegranate, 10. [CrossRef]

McAdams, Dan. 1985. Power, Intimacy, and the Life Story: Personological Inquiries into Identity. New York: Guilford Press. ISBN 9780898625066.

McAdams, Dan. 2001. The psychology of life stories. Review of General Psychology 5: 100-22. [CrossRef]

McAdams, Dan, and Erika Manczak. 2015. Personality and the Life Story. In APA Handbooks in Psychology ${ }^{\circledR} A P A$ Handbook of Personality and Social Psychology, Vol. 4. Personality Processes and Individual Differences. Edited by Mario Mikulincer, Phillip Shaver, Lynne Cooper and Randy Larsen. Washington, DC: American Psychological Association, pp. 425-46. [CrossRef]

McAdams, Dan, Barry Hoffman, Elizabeth Mansfiels, and Rodney Day. 1996. Themes of Agency and Communion in Significant Autobiographical scenes. Journal of Personality 64: 339-77. [CrossRef]

McLean, Kate, and Michael Pratt. 2006. Life's Little (and Big) Lessons: Identity Statuses and Meaning-Making in the turning point narratives of Emerging adults. Development Psychology 42: 714-22. [CrossRef]

Mitchell, Katharyne. 2003. Educating the National Citizen in Neoliberal Times: From the Multicultural Self to the Strategic Cosmopolitan. Transactions of the Institute of British Geographers 28: 387-403. [CrossRef]

Noel, Daniel. 1997. The Soul of Shamanism: Western Fantasies, Imaginal Realities. New York: Continuum. ISBN 0826409326.

Noll, Richard. 1989. What has really been learned about shamanism? Journal of Psychoactive Drugs 21: 47-50. [CrossRef] [PubMed]

Pals, Jennifer. 2006. Narrative Identity Processing of Difficult Life Experiences: Pathways of Personality Development and Positive Self Transformation in Adulthood. Journal of Personality 74: 1079-109. [CrossRef]

Peletz, Michael. 2006. Transgenderism and gender pluralism in Southeast Asia since early modern times. Current Psychology 47: 309-40. [CrossRef]

Pratt, Christina. 2007. An Encyclopedia of Shamanism, Volume 1. New York: The Rosen Publishing Group, Inc. ISBN 978-1-4042-1040-0.

Pritzker, Barry. 2000. A Native American Encyclopedia: History, Culture, and Peoples. Oxford: Oxford University Press. ISBN 9780195138979.

Reinhard, Johan. 1976. Shamanism and spirit possession: The definition problem. In Spirit Possession in The Nepal Himalayas. Edited by John Hitchcock and Rex Jones. Warminster: Aris and Philips, pp. 12-20. ISBN 085668029X.

Schefold, Reimar. 1988. Lia; Das Grosse Ritual auf den Mentawai-Inseln (Indonesien). Berlin: Reimer. ISBN 3496009381.

Singh, Manvir. 2018. The cultural evolution of shamanism. Behavioral and Brain Sciences 41: 1-62. [CrossRef] [PubMed]

Taussig, Michael. 1991. Shamanism, Colonialism and the Wild Man. A Study in Terror and Healing. Chicago: University of Chicago Press. ISBN 0226790134. 
Townsend, Joan. 2005. Individualist religious movements: Core and neo-shamanism. Anthropology of Consciousness 15: 1-9. [CrossRef]

Von Stuckrad, Kocku. 2005. Constructions, Normatives, Identities: Recent Studies on Shamanism and Neo-Shamanism. Religious Studies Review 31: 123-28. [CrossRef]

Wallis, Robert. 1999. Altered States, Conflicting Cultures: Shamans, Neo-shamans and Academics. Anthropology of Consciousness 10: 41-49. [CrossRef]

Wallis, Robert. 2003. Shamans/Neo-Shamans: Ecstasy, Alternative Archaeologies, and Contemporary Pagans. London: Routledge. ISBN 041530203X.

Walsh, Roger. 1990. The Spirit of Shamanism. New York: Jeremy P. Tarcher, Inc. ISBN 0874775620.

Walter, Mariko, and Eva Jane Neumann Fridman, eds. 2004. Shamanism: An Encyclopedia of World Beliefs, Practices, and Culture. Santa Barbara: Abc-clio. ISBN 1576076458.

Wilson, David. 2013. Redefining Shamanisms: Spiritualist Mediums and Other Traditional Shamans as Apprenticeship Outcomes. London: Bloomsbury. ISBN 9781441159502.

Znamenski, Andrei. 2007. The Beauty of the Primitive: Shamanism and the Western Imagination. Oxford: Oxford University Press. ISBN 0195172310.

(C) 2020 by the authors. Licensee MDPI, Basel, Switzerland. This article is an open access article distributed under the terms and conditions of the Creative Commons Attribution (CC BY) license (http://creativecommons.org/licenses/by/4.0/). 